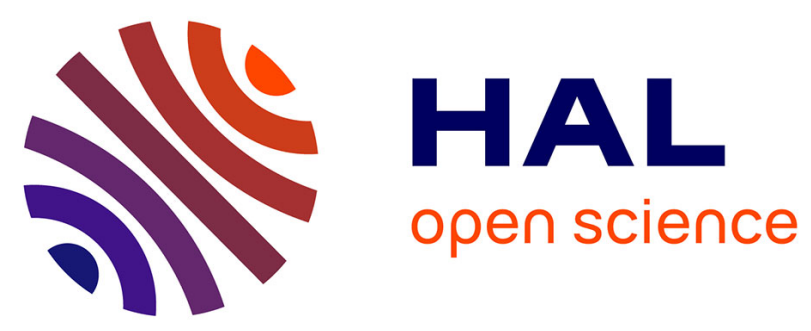

\title{
Early Intervention in Poor Families Confronted With Alcohol Abuse and Violence: Impact on Families' Social Integration and Parenting
}

\author{
Annick-Camille Dumaret, Marie Constantin-Kuntz, Maurice Titran
}

\section{To cite this version:}

Annick-Camille Dumaret, Marie Constantin-Kuntz, Maurice Titran. Early Intervention in Poor Families Confronted With Alcohol Abuse and Violence: Impact on Families' Social Integration and Parenting: impact of early intervention within alcoholic and poor families. Families in Society: the Journal of Contemporary Social Services, 2009, 90 (1), pp.11-17. 10.1606/1044-3894.3840 . inserm-00469579

HAL Id: inserm-00469579 https://www.hal.inserm.fr/inserm-00469579

Submitted on 1 Apr 2010

HAL is a multi-disciplinary open access archive for the deposit and dissemination of scientific research documents, whether they are published or not. The documents may come from teaching and research institutions in France or abroad, or from public or private research centers.
L'archive ouverte pluridisciplinaire HAL, est destinée au dépôt et à la diffusion de documents scientifiques de niveau recherche, publiés ou non, émanant des établissements d'enseignement et de recherche français ou étrangers, des laboratoires publics ou privés. 
Paru dans Families In Society, 2009, 90, n¹, 11-17

DOI:10.1606/1044-3894.3840

\title{
Early Intervention in Poor Families Confronted With Alcohol Abuse and Violence: Impact on Families' Social Integration and Parenting
}

\author{
Annick-Camille Dumaret, Marie Constantin-Kuntz, and Maurice Titran
}

\begin{abstract}
To help families challenged by transgenerational problems, substance abuse, and violence, support strategies require professionals who understand their specific needs and inspire trust. Such support, provided by a group consisting of professionals, volunteers, and families, was assessed by a follow-up study. The outcome of 22 families was observed an average of 7 years after their participation in the group ended. Results show that most parents recovered a significant degree of social autonomy and developed the capacity to nurture their children. Alcohol abuse, violence, and child neglect decreased significantly. Such an intensive approach enhances individual and professional practices and prevents adverse childhood experiences, thus reducing welfare costs. But such support systems require accessible structures in order to avoid discontinuities in care.
\end{abstract}

Key words:

Families at risk ; early intervention ; fetal alcohol spectrum disorder ; child neglect and abuse ; family violence ; intergration 
For over 15 years in Roubaix, in Northern France, the "Tuesday Group," a family support service, has been operating in a day treatment center for young children. Families from extremely poor environments and those suffering from alcoholism, domestic violence, and mental health problems are referred to this support group. Its purpose is to prevent future alcohol-affected pregnancies, reduce child abuse, and enhance parenting skills. The center's director requested the cooperation of an outside researcher from the Institut National de la Santé et de la Recherche Médicale research team (Dumaret, 2004) working with institutions that also worked on dysfunctional child-parent relationships and child maltreatment. In each location, a follow-up study was conducted to examine the impact of these specific aid strategies on families' outcomes. Initial research conducted by Roubaix's Tuesday Group professionals dealt with the intergenerational impact of prenatal alcohol exposure on maternal and child development. This article focuses on parental perception of care, social integration, and the family relationships of parents who participated in this support group.

\section{Introduction}

A significant body of research associates psychiatric illness, drug abuse, parental cognitive deficiency, and poverty-stricken environments with parenting problems, as well as with child abuse and neglect (Booth, Booth, \& McConnell, 2005; Dunst, Trivette, \& Jodry, 1997; Kumpfer \& Bays, 1995; Oyserman, Mowbray, Meares, \& Firminger, 2000). Social exclusion, stress, and poor social and family networks have also been associated with these problems (Coohey, 1996; Ethier, Lacharite, \& Couture, 1995; McLoyd, 1990). This explains why numerous early-intervention programs providing pediatric education and family support services have been oriented toward disadvantaged or at-risk families (Meisels \& Shonkoff, 2000). Positive effects on parental competence and on the quality of parent-child relationships have been demonstrated. In particular, the study by Olds and colleagues (Olds, Henderson, \& Kitzman, 1995, Olds et al., 1997) in underprivileged environments shows a decrease in out-of-home placements and emergency hospitalizations for children, and improvement in socioprofessional adjustment for mothers. In certain situations (mental retardation, substance abuse, mental health problems, etc.), the programs were more effective when tangible services were offered to families and when they were initiated during the prenatal period (Black et al., 1994; Fraser, Armstrong, Morris, \& Dadds, 2000; Grant, Ernst, Pagalilauan, \& Streissguth, 2003). The effectiveness of these early interventions was linked to their long duration and with the families' involvement in the care group (Earls, 1998). The importance of the relationship between parents and program staff or professionals has also been asserted (Korchmacher, 1998; Brooks-Gunn, Berlin, \& Fuligni, 2000; Olds, Sadler, \& Kitzman, 2007).

However, long-term effects are limited in situations of continuing poverty and accumulated intergenerational adversity (Berlin, O’Neal, \& Brooks-Gunn, 1998, Bifulco, Moran, Ball, Jacobs, Baines et al., 2002). These families are often alienated from the health and social communities and feel misunderstood by professionals, who need to find better ways of interacting with them.

France does not have such intervention programs but has a considerable Child Welfare and Protection system in place, along with various regional and specialized local agencies, such as the center for young children presented here. First, it might be useful to remind ourselves of the workings of the French Child Welfare and Protection system. This system has been run by local authorities ever since 
decentralization took place in 1983. Local authorities are autonomous and are made up of three departments: (1) the Social Services department and social welfare agencies; (2) the Protection Maternelle Infantile, or PMI (department for the protection of maternal and children's health, created after World War II), which looks after pregnant women and children from birth through 6 years of age; and (3) the Aide sociale à l'enfance (child welfare services), which support families at risk and those suffering from social difficulties through two types of measures: (a) administrative measures, mostly in the home, providing financial allowances and educational support, and (b) judicial measures, enacted by court orders, which protect children in danger, usually through placements. Although these departments are independent, continuity exists among them through networks of social, medical, and educational teams. ${ }^{1}$

\section{Context of the Study}

Over 200 day treatment centers (Centres d'Action Médico-Sociale Précoce, or CAMSP) care for children from birth through 6 years of age with motor, mental, and sensory impairment, and offer family counseling and child care. Their dual screening and treatment role explains the teams' multidisciplinary makeup (a pediatrician, a psychologist, a social worker, neuropsychiatrists, therapists, teachers, et al.) and their joint financing (PMI: 20\%, Social Security: 80\%). However, they are autonomous and each functions in its own way.

Of all these centers, the CAMSP of Roubaix occupies a special place, literally and figuratively: In 1981, it was intentionally moved to the heart of an economically depressed area. The staff had made two observations: Parents generally fear judgmental attitudes from professionals, which, along with the dizzying multitude of professionals catering to their needs, leads families to avoid social and health services and consequently excludes children from care. It was therefore vital to better understand family needs and to develop or revive trust in these professionals by offering specialized, unobtrusive assistance. The Tuesday Group (TG) was created in 1985-86 by the CAMSP's director (a pediatrician) and a social worker. Its objective was to promote parental competence and behavior, which would increase their capacity to successfully nurture their children (Titran 1993, 2004). Its outlook could be compared to that of the Steep Program (Erickson \& Egeland, 1999): Parents are regarded as individuals in difficulty, living in insecure conditions under constant stress, rather than as "deficient" or abusive parents.

The theoretical basis for this new approach lies in creating guidance and support strategies in ways that respect families, their values, and their social identity, because primary responsibility for the well-being and development of children rests with families. The professionals' underlying hypothesis was that parents would accept help and take responsibility for their children's health and their own.

For years, this support group has been operating according to the same processes, based on warm and informal exchanges among families, professionals, and volunteers. It primarily targets families struggling with transgenerational alcoholism. Generally, families are directed to the group by social workers from the PMI, Child Welfare services, or the CAMSP pediatrician during consultation. The staff is made

\footnotetext{
${ }^{1}$ In 2005, 133,400 children living with their families benefited from educational measures and another 134,400 aged 0-20 were placed in foster families or in institutions (75\% of them through court orders).
} 
up of professionals from CAMSP and other institutions (pediatricians, social workers, teachers, therapists, et al.) and volunteers (including professionals from other institutions and paraprofessionals).

On average, 15 families participate in each meeting, attending on a strictly voluntary basis and participating at their own rhythm. Meetings are held year-round, one afternoon a week, for approximately 2 hours. There is no preestablished agenda: parents themselves decide on the discussion topics, about which they can exchange freely. Participants share their experiences and their knowledge of activities from daily life (e.g., manufacturing small items, sewing, housework, and cooking). Manual activities provide an opportunity to spend time together and share know-how, allowing each person's talents to be emphasized through everyday acts. Children can also participate in group games and activities, or be involved in individual treatment (speech therapy, psychomotility, etc.). Fathers sometimes attend the group, but most often it is mothers who come with their children. Group sessions can also bring together parents and children who are in placements. Transportation is arranged for parents who cannot use public transportation. Other activities include outings and one week of summer vacation. The only exclusionary criteria are violence and severe verbal or physical aggressiveness. Families leave the TG when their children reach the age of 6 .

Close observation of both parents and children, and of mother-child interaction in the TG allows professionals and volunteers to identify family needs, and lays the groundwork for constructive support. At the end of each meeting, a recap by team members analyzes the progress made by families; the team may also elect to contact other social or medical services.

The key concept is continuously accessible support; families always meet with the same staff members. Parents are shown new frames of reference with regard to time and space (e.g., being on time to organized outings and to appointments for child treatment). They (re)discover their own abilities and experience new ways of operating in social relationships. As shown elsewhere, helping families who are grappling with parenting difficulties and alcohol issues is an overwhelming challenge, requiring multiple levels of support (Peterson, Gable, \& Saldana, 1996). Thus, both professionals and volunteers help families deal with professionals in the outside world (e.g., schools, the justice system) and enable them to make use of other resources and opportunities within the community to develop their own potential.

\section{Materials and Methods}

Evaluating human service interventions is difficult, as shown by Heneghan, Horwitz, and Leventhal (1996) in their methodological review: It implies having standardized assessment of both risks and multiple outcomes. That is precisely what we attempted to do by studying the impact that the group has on families, parents, and children. Part of the methodology used in our research program was adapted to this population; children's and parents' assessments were conducted by evaluators from outside the institution (Dumaret, 2004). Because three quarters of the families lived below the poverty line (although all had access to minimum levels of subsidies and health allowances), compensation was offered at the end of the assessments in the form of merchandise waivers (valued at approximately 30 euros).

This article examines the main outcomes for families and parent-child relationships. It was also interesting to find out from the families themselves which aspects they found beneficial to themselves and to their children. Other publications have 
described the impact of fetal alcohol spectrum disorders on the cognitive functions of mothers and on children's development (Dumaret \& Titran, 2004, Dumaret, Cousin, \& Titran, (2008).

Among the formulated hypotheses, and given the TG's objectives, we postulated that this support, provided over a long period of time, would allow parents to face addiction problems, and that social exclusion and serious neglect would significantly diminish.

\section{Family Selection, Ethical Considerations, and Procedures}

In this historical prospective study, the following criteria were established for family selection: (1) families confronted with alcoholism who had participated in the group for a year or more, (2) children who were taken on before the age of 4.5, and (3) assessments that were carried out more than 5 years after group participation ended.

Out of 58 families who attended the TG between 1989 and 1995, 22 met these criteria. A letter was sent by the CAMSP director asking families to help evaluate the support group, adding that it would be useful to current families. Extensive research and the participation of other social and medical services were all required to gain access to these families (missed appointments, abrupt relocations, etc.). In some cases, the pediatrician went to families' homes to ask for their help and introduced the researcher to them. All parents participating in the study signed a consent form and received a guarantee of confidentiality.

\section{Data Collection and Analysis}

Given such a small sample, we opted for a qualitative study with a comprehensive, psychosocial approach. Data for the study were collected from several sources, past and present.

CAMSP records (children's medical and social files) often provided detailed descriptions of family antecedents and evolving family and parent-child relations during their involvement with the support group. Data on children in danger were obtained from Child Welfare services; and data on mentally deficient parents, from legal guardian services. Data files on children were consulted after receiving parental authorization.

Semistructured interviews (1-1.5 hours long) were conducted by an outside researcher (a psychologist). They dealt with family history, household and financial management, social relationships, parental roles, health (alcohol use in the couple and the extended family, health care habits), and memories of the TG. In terms of relationships, in addition to hobbies and outside interests, research also examined subjects' support networks, made up of their own parents and siblings, their extended family, friends, neighbors, and other sources of social support (following the model of Ethier et al.'s 1995 psychosocial interview scale). Foster families were only interviewed by telephone.

The interviews were then interpreted through a classic content analysis. A family participation index was created to measure the frequency of participation by detailing each family's TG attendance. The sociodemographic data of the survey were synthesized into variables: family resources (salary, or minimum insertion income $[R M I]$, or allowance for disabled adults $[A A H]$ ), family type (single- or two-parent families), and past and present out-of-home placements. Family relationships were rated on a scale from "inexistent" to "supportive."

All of the mothers accepted to participate: 21 were interviewed twice; one was highly hesitant and not very forthcoming. Eight fathers or partners were also interviewed, out 
of which two were interviewed twice. Fathers were interviewed separately from mothers because many worked. The majority of interviews were conducted in the home.

\section{Results}

On average, parents and children participated in the group for approximately 30 months. Outcomes were ascertained on average 7 years after members left the group. Mothers were generally around 40 years old.

\section{Family Situations at Time of Admission and at the End of Their Participation}

All families were White. All the maternal grandmothers, except in two cases, had been alcoholic, and in half the families, alcohol-dependent for two generations. Sixteen spouses were alcoholic; 14 mothers had fetal alcohol spectrum disorders: fetal alcohol syndrome (FAS) and fetal alcohol effects (FAE). None had a profession; none had completed high school. None had a diploma, except for two mothers who began drinking later in life than the others, but who never finished secondary school.

Depression, although undiagnosed, was present in the maternal families. Alcohol dependency was associated with severe neglect and abuse at home during childhood and adolescence for 18 mothers (82\%), including sexual abuse and out-of-home placements. It was also linked to ongoing domestic violence (violence toward mothers and/or their children) in 17 families (77\%). Furthermore, half of the mothers had been suffering from personality disorders or mental illness (including hospitalizations or institutional reports of psychiatric treatment). For half of the families, judicial educational measures for the children had ceased during TG participation or afterward. Mothers exhibiting the most severe mental health problems participated for the longest period of time; those who were mentally deficient participated irregularly. Two violent mothers had been asked to leave the group, one after 13 months, the other after 3 years.

\section{Perceived Support From Parents}

Today, the parents all fondly remember having been warmly welcomed into the group, without feeling judged. They felt treated with civility and respect, despite society's often disparaging attitudes toward them: "As soon as I left this place, people looked at me as though I were a tramp. Here I'm listened to, I'm acknowledged." The absence of restrictions and the group framework's great flexibility reassured them and made them want to return.

Mothers enjoyed the manual activities. The familiar activities, which require no training, brought about a big boost in self-confidence and served as a medium for verbal exchanges.

The confidence they gradually acquired enabled parents to talk about their past to the group and discover they weren't the only ones to have endured such problems. A way of expressing past trauma was thus able to take place: "We even spoke of very personal and violent things; you see what I mean." "We were able to talk, and let out the problems we had." Parents stated that they became more and more involved with the TG and found support in its group dynamics. Thus, some mothers undertook one or several alcohol detoxification treatments: "I decided to stop after seeing four alcoholic mothers; their children were in care." "A mother was tipsy when she arrived. I told myself: it's not becoming to see a woman drinking, it's disgusting to drink. It must be the same for me; I have to stop."

Little by little, participants (re)discovered the pleasure of being in contact with others, 
and opened up to the outside world. For instance, a father got his driver's license after having participated in group trips: "Afterwards, I really took off. Otherwise, I think I would have just kept hanging around the area." After leaving the TG, five women entered private organizations (like ATD Fourth World), including four ex-alcoholic mothers who became mentors in an organization counseling pregnant alcoholic women.

The layout of the center allowed for a reassuring design, separating parents and children: The latter could play at a distance while remaining within sight of parents. This physical separation allowed them to get out of an enmeshed relationship: "She was a child who was very attached to her mother; she cried a lot and had to be constantly reassured ... it helped her, after a year, because I felt she was moving away from me." In addition, by seeing their child playing with others, parents were able to see progress: "If my girl doesn't present any more problems, it's because she came here; it opened her up to do theater with other children."

\section{Outcome of Families}

Among short-term effects, institutional files noted the improving health of the youngest children (those born last): higher birth size and weight, absence of malformations, no postnatal deaths.

The elimination of maternal alcoholism triggered improvements in families' daily lives and in overall well-being: "When drinking, we feel degraded; we no longer participate in activities like before. And in the group, we rediscovered our autonomy." Mothers who stopped drinking (9 out of 11) separated from alcoholic fathers (or the partner also stopped), and their subsequent spouses were supportive, nonalcoholic partners. In three quarters of cases, severe intrafamily violence and neglect disappeared (Table 1).

Interview analysis allowed a classification of families by evolution and degree of autonomy. Three profiles emerged: The first was made up of families whose situations have improved significantly. Only a slight shift was observed in the second, whereas in the last one no change in family functioning was noted.

<Insert Table 1 about here.>

1. Twelve families were autonomous (A families): Their principal income was a salary. Six out of seven mothers were no longer addicted to alcohol. Four mothers found employment; another received an auxiliary nursing diploma. There were only five single-parent families (divorced or widowed mothers). Relationships with family members and relatives were varied; Social isolation had strongly diminished.

2. In six families, the situation had slightly improved and "stabilized" (S families): They were supported by welfare allowances, and four mothers were under guardianship. The majority of these mothers were taking neuroleptics and antidepressants; the only alcoholic mother had stopped drinking. Four of the mothers felt isolated because they were not raising their children. Spouses and families were less supportive; family circles were more limited.

3. The situation in four families ( $U$ families) remained unchanged: Three mothers were cognitive-deficient, the fourth was borderline. All were supported by social welfare or allowances for disabled persons. Alcohol abuse continued in three families, although two mothers claimed they had stopped drinking. Family relationships were problematic; support was solely provided by social workers, often imposed by court 
order.

\section{Parent-Child Relations}

These 22 mothers had 98 children; half of them were or had been in out-of-home placements. Sixty-two were children under 18 years of age, and 17 were still in care (Table 1). In the majority of families, parental responsibility belonged to the mother; in a third of cases it belonged to both parents. For children in out-of-home placement, parental rights were shared with local authorities.

In the A families, parents were raising all their children (in three families, children leaving out-of-home placement were reunited with them). In half of the families, the parent who did not have custody met with his or her children regularly. Compared to the other families, these parents seemed to have the greatest capacity for understanding their children's needs, and they spoke of their pleasure in parenting (sharing activities, outings, hugging their children). In their parental role, they emphasized emotional relations and communication with their children over education and surveillance. These parents were involved in their children's studies, and all accepted that their children receive psychological or psychiatric care. In addition, a third of these families requested preventive educational measures for their adolescents. We note that these parents possessed a certain capacity to critique their own educational methods. For example, a father, who had been placed in care during his adolescence, asked himself: "Did we do the right thing? I educated them as best I could, but it wasn't easy. Did we do well?" A mother, whose first two children had been raised by her ex-husband, added: My two oldest children were placed in care, and I'm sick over it; it makes me suffer. Eighty percent of it is our fault. I'm not sure I was a good mother; if I had been, maybe I would have realized that they had psychological problems. I didn't fully grasp their distress.

Two thirds of $\mathrm{S}$ family children were in out-of-home placements or in medical institutions. Only one of the two-parent families raised all their children. The mothers expressed distress at being separated from them but felt that the children were rather well-off in their foster families. The child-mother relationship was stable. They saw each other on weekends, or once a week at home, and during vacations), but children were in irregular contact, or none at all, with their biological fathers.

In the first two groups $(\mathrm{A}, \mathrm{S})$, parents mentioned their inability to place limits on their children in educational matters or to say "no" to them. Some tried to control themselves, indicating that they preferred smoking or yelling to hitting their children. Although they were able to keep from relapsing into alcoholism, this was not true of sexual abuse. However, although mothers were unable to anticipate the behavior of certain family members, they reported abuse to the police, which would have been unthinkable before. Psychological care was set up earlier than for older siblings who suffered identical trauma: "I asked the judge for assistance because I knew that abused children don't do well.... Even if they didn't talk with me, they could at least talk to someone else about it."

In U families, parents still didn't grasp their children's real needs. For them, childraising values entailed supervision and authority. Incest often occurred among family members. In three families, children were in out-of-home placements; in the other one, the family failed to heed any educational measures. Fathers were absent (dead, imprisoned, or mentally ill). For all these families, irregular attendance of the support group was observed, and children did not receive regular care. 


\section{Discussion}

Promoting parent-child health and well-being in poverty-stricken families suffering from multiple problems requires, first and foremost, an accurate evaluation of their specific needs. This is why a team in a day treatment center for young children created a group to develop supportive strategies adapted to each family situation. This group regularly brings together professionals, volunteers, and families.

Families who were thus looked after for at least 1 year were assessed through an outside evaluation conducted an average of 7 years after they left the group. The 22 parents agreed to cooperate, indicating that the trust they felt toward the center's pediatrician extended to the researchers. This deserves mention, given that families with transgenerational problems or mental limitations rarely participate in research; it is for this reason they are called "invisible families" by Keltner, Wise, and Taylor (1999, p. 55).

Data have shown the crushing weight of adverse environments and risk factors that these women, over two generations of alcohol abuse, have had to deal with: fetal alcohol spectrum disorders, mental health problems, and depression. The high proportion of children in care was due to important maternal deficiencies (Booth et al., 2005) and to violence, which was rampant in the overwhelming majority of families when they were steered toward the group. In spite of the potential weaknesses due to retrospective maternal family data, these results may be compared to those found in other population-based studies (Dube, Anta, Felitti, Croft, Edwards, et al., 2001; Harmer \& Sanderson, 1999). They can also be compared to results on women with fetal alcohol spectrum disorders detailing their poor quality-of-life issues, parenting difficulties, as well as high rates of psychiatric and behavioral problems (Streissguth, Bookstein, Barr, Sampson, O’Malley, et al., 2004, Grant, Huggins, Connor, \& Streissguth, 2005). Constructive support has motivated the large majority of alcoholic mothers to enter detoxification. These findings need to be further validated with a complementary study (e.g., of families who participated after 1995), and data should be replicated with a larger sample. However, the current results are corroborated by those from assistance programs for women dealing with alcohol and drug abuse in Washington State (Grant et al., 2003).

By improving contextual conditions, parental functioning changed. Violence and severe neglect largely decreased; this result was correlated to the separation from alcoholic spouses by mothers who stopped drinking. The percentage of families that won back child custody is higher than in some other family support programs (Heneghan et al., 1996). Most of the families emerged from social exclusion. It is in the sphere of improving parent-child relationships, and of social support networks within the community, that families who have become autonomous differ from the others. Even if families with mental health problems still have parenting problems, no new child has been placed by court order, even among those born after the end of group participation. Such results are consistent with those on early intervention in very disadvantaged families, and with those on the importance of a supportive partner's presence (Egeland \& Susman-Stillman, 1996; Olds et al., 1995, 1997).

Nevertheless, some of data based on self-reporting may be biased. We attempted to validate mothers' reports by interviewing social workers and consulting the records of local authorities, but maltreatment may not have been detected by health and social services. Furthermore, the fact that a family is no longer listed with Child Protection services does not guarantee that other forms of child abuse will not reoccur in the future. 
In the absence of a control group, the causal effect of these strategies cannot be proved; this study remains descriptive. Furthermore, it is possible that mothers referred to the group by medical or social services and who participated for over a year were more compliant than the others; this would explain some of the positive findings. Similar results were observed in the two other French centers we worked with (Dumaret \& Picchi, 2005; Dumaret, Mackiewicz, \& Bittencourt-Ribeiro, 2007). Whatever the center, meeting with parents to look at their suffering and not their shortcomings or their problems was a precursor to treatment: Their first impressions played a key role in the creation and the sustaining of a guidance and therapeutic alliance. Families appreciated the positive welcome by the staff, the informal support, and the multidisciplinary, comprehensive services. Through their motility and sensory aspects, the manual activities in particular helped to lower parents' anxiety and open the door to verbal expression. Trust placed in the professionals gave parents a certain self-esteem in return; they took the initiative in treatment (e.g., ending alcohol and drug use) and mentioned having found joy in relationships with their children. Helped by a supportive network (social workers, etc.), families gradually took on the ability to positively interact with their children and acquired or discovered the ability to ask for help when necessary.

In this group, the leadership is assumed by a pediatrician. Such a role as family health advisor is important, as noted by the American Academy of Pediatrics (2001). But it is the entire group (professionals, volunteers, and families) that helps to better identify families' strengths and difficulties. This way of operating also allowed professionals to be more effective. Thanks to the psychological involvement of all participants, positive effects remain visible in the long term, as noted in other research (Jack, 2000).

However, some families remain on the brink of poverty, living in a precarious equilibrium, particularly when accumulated risk factors persist within the families. To be effective, guidance strategies require long-term cooperation and coordination among professionals caring for adults and those caring for children. With such early intervention bringing together social and health fields, prevention should improve and welfare costs could be reduced. This is not merely a question of technical means, but also one of reorganizing existing human resources.

\section{References}

American Academy of Pediatrics. (2001). The pediatrician's role in family support programs. Pediatrics, 107, 195-197.

Berlin, L. J., O’Neal, C. R., \& Brooks-Gunn, J. (1998). What makes early intervention programs work? The program, its participants, and their interaction. Zero to Three, 18, 4-15.

Bifulco, A., Moran, P. M., Ball, C., Jacobs C., Baines R., Bunn A. et al. (2002). Childhood adversity, parental vulnerability and disorder: Examining intergenerational transmission of risk. Journal of Child Psychology and Psychiatry, 43, 1075-1086.

Black, M., Nair, P., Kight, C., Wachtel, R., Roby, P., \& Schuler, M. (1994). Parenting and early development among children of drug-abusing women: Effects of home intervention. Pediatrics, 94, 440-448.

Booth, T., Booth, W., \& McConnell, D. (2005). Care proceedings and parents with learning difficulties: Comparative prevalence and outcome in an English and Australian court sample. Child and Family Social Work, 10, 353-360. 
Brooks-Gunn, J., Berlin, L. J., \& Fuligni, A. S. (2000). Early childhood intervention programs: What about the family? In S. J. Meisels \& J. P. Shonkoff (Eds.), Handbook of early childhood intervention (2nd ed., pp. 549-588). New York: Cambridge University Press.

Coohey, C. (1996). Child mistreatment: Testing the social isolation hypothesis. Child Abuse and Neglect, 30, 241-254.

Dube, S. R., Anta, R. F., Felitti, J., Croft J. B., Edwards V.J., \& Giles W. H. (2001). Growing up with parental alcohol abuse: Exposure to childhood abuse, neglect, and household dysfunction. Child Abuse and Neglect, 25, 1627-1640.

Dumaret, A. C. (2004). Evaluation of intervention in families exhibiting psychosocial or psychiatric risks: an explanatory approach. In Haddad, A., Guédeney, A., Greacen T. (Ed.), Infant and Child Mental Health: Prevention and care (pp. 121-131). Ramonville Saint Agne: Erès.

Dumaret, A. C., \& Titran, M. (2004). Strategies of intervention for families with multiple risks: From care to autonomy. Research report to local and regional authorities of North and Pas-de-Calais.

Dumaret, A. C., \& Picchi, V. (2005) Early intervention: Psychosocial outcome of families and children's development. Annales Médico-Psycholologiques, 163, 476-485.

Dumaret A. C., Mackiewicz, M. P., \& Bittencourt-Ribeiro, F. (2007). Child Protection and evaluation: a multidisciplinary approach crossing data and perceptions from all the actors. Sociétés et jeunesses en difficultés. Revue Pluridisciplinaire de Recherches. Retrieved April 3, 2007, from http://sejed.revues.org.document350.html.

Dumaret, A. C., Cousin, M., \& Titran, M. (2008, in press). Child development in vulnerable families with intergenerational alcoholism. Alcoologie et Addictologie, 30.

Dunst, C. J., Trivette, C. M., \& Jodry, W. (1997). Influences of social support on children with disabilities and their families. In M. J. Guralnick (Ed.), Effectiveness of early intervention (pp. 499-522). Baltimore: Brookes.

Earls, F. (1998). Positive effects of prenatal and early childhood intervention. Journal of the American Medical Association, 280, 1271-1273.

Egeland, B., \& Susman-Stillman, A. (1996). Dissociation as mediator of child abuse across generations. Child Abuse and Neglect, 20, 1123-1132.

Erickson, M. F., \& Egeland, B. (1999). The STEEP Program: Linking theory and research to practice. Zero to Three, 20, 11-16.

Ethier, L. S., Lacharité, C., \& Couture, G., (1995). Childhood adversity, parental stress, and depression of negligent mothers. Child Abuse and Neglect, 19, 619632.

Fraser, J. A., Armstrong, K. L., Morris, J. P., \& Dadds, M. R. (2000). Home visiting intervention for vulnerable families with newborns: Follow-up results of a randomized controlled trial. Child Abuse and Neglect, 24, 1399-1429.

Grant, T., Ernst, C. C., Pagalilauan, G., \& Streissguth, A. (2003). Postprogram follow-up effects of paraprofessional intervention with high-risk women who abused alcohol and drugs during pregnancy. Journal of Community Psychology, $31,211-222$.

Grant, T., Huggins, J., Connor, P., \& Streissguth, A. (2005). Quality of life and psychosocial profile among young women with fetal alcohol spectrum 
disorders. Mental Health Aspects of Developmental Disabilities, 8, 33-39.

Harmer, A. L., \& Sanderson, J. (1999). Influence of negative childhood experience on psychological, functioning, social support, and parenting for mothers recovering from addiction. Child Abuse and Neglect, 23, 421-433.

Heneghan, A. M., Horwitz, S. M., \& Leventhal, J. M. (1996). Evaluating intensive family preservation programs: A methodological review. Pediatrics, 97, 535542.

Jack, G. (2000). Ecological influences on parenting and child development. British Journal of Social Work, 30, 703-720.

Keltner, B. R., Wise, L. A., \& Taylor, G. (1999). Mothers with intellectual limitations and their 2-year-old children's developmental outcomes. Journal of Intellectual and Developmental Disability, 24, 45-57.

Korchmacher, J. (1998). Examining the service provider in early intervention. Zero to Three, 18, 17-22.

Kumpfer, K. L., \& Bays, J. (1995). Child abuse and tobacco, alcohol and other drug abuse: Causality, coincidence or controversy? In J. H. Jaffe (Ed.), Encyclopedia of drugs and alcohol (pp. 217-222). New York: Macmillan.

Meisels, S. J., \& Shonkoff, J. P. (Eds.). (2000). Handbook of early childhood intervention. New York: Cambridge University Press.

McLoyd, V. C. (1990). The impact of economic hardship on black families and children: Psychological distress, parenting and socioemotional development. Child Development, 61, 311-346.

Olds, D. L., Henderson, C. R., \& Kitzman, H. (1995). Effects of prenatal and infancy nurse home visitation on surveillance and child maltreatment. Pediatrics, 3, $365-372$.

Olds, D. L., Eckenrode, J., Henderson C. R., Kitzman R. N., Powers, J., Cole, R., et al. (1997). Long-term effects of nurse home visitation on maternal life course and child abuse and neglect: 15 -year follow-up of a randomized controlled trial. Journal of the American Medical Association, 278, 637-643.

Olds, D. L., Sadler, L., \& Kitzman, H. (2007). Programs for parents of infants and toddlers: Recent evidence from randomized trials. Journal of Child Psychology and Psychiatry, 48, 355-391.

Oyserman, D., Mowbray, C. T., Meares, P. A., \& Firminger, K. B. (2000). Parenting among mothers with a serious mental illness. American Journal of Orthopsychiatry, 70, 296-315.

Peterson, L., Gable, S., \& Saldana, L. (1996). Treatment of maternal addiction to prevent child abuse and neglect. Addictive Behaviors, 21, 789-801.

Streissguth, A, Bookstein, F. L., Barr, H. M., Sampson P. D., O’Malley K., \& Young J. K. (2004). Risk factors for adverse life outcomes in fetal alcohol syndrome and fetal alcohol effects. Developmental and Behavioral Pediatrics, 25, 228238.

Titran, M. (1993). Bearing Witness: The Tuesday Group Archives of Public Health, 51, 135-39.

Titran, M. (2004). Proper parental treatment and precariousness. Pratiques Psychologiques, 10, 65-77.

Annick-Camille Dumaret, $\mathbf{P h D}$, is a psychologist and researcher at the Institut 
National de la Santé et de la Recherche Médicale. Marie Constantin-Kuntz, MS, is a psychologist at the Centre Médico-Psychologique de Courbevoie. Maurice Titran, MD, is a pediatrician and the director of CAMSP de Roubaix, Centre hospitalier de Roubaix. Correspondence regarding this manuscript can be addressed to the first author at dumaret@vjf.cnrs.fr or

CERMES-Inserm U750, site CNRS, 7 rue Guy Môquet, F-94801 Villejuif Cedex, France.

Author's note. Local authorities, the regional councils of North and Pas-de-Calais, and the Fondation de France provided grants for this research, which was conducted at the Centre de Recherche Médecine, Sciences, Santé et Société, (CERMES) in Villejuif, France.

Manuscript received: October 5, 2007

Revised: January 18, 2008

Accepted: March 10, 2008 